\title{
Adverse effects of khat: a review
}

\section{Glenice Cox \& Hagen Rampes}

Abstract Catha edulis (khat) is a plant grown in the countries around the Red Sea and on the eastern coast of Africa. Its leaves are chewed by the local people for their stimulant action. Its principal active constituents are cathinone and cathine, which have sympathomimetic actions. Migration of Africans from these countries has spread the habit of khat chewing to the West. Chewing khat has a number of important psychological and physical sequelae. 'Khat-related' psychosis is very similar to that seen following use of amphetamines.

\section{Botany}

Khat grows wild in countries bordering the Red Sea and along the east coast of Africa. The people of these countries have chewed khat for centuries. There are several names for the plant, depending on its origin: chat, qat, qaad, jaad, miraa, mairungi, cat and catha. In most of the Western literature, it is referred to as khat.

Khat is an evergreen shrub, which is cultivated as a bush or small tree. The leaves have an aromatic odour. The taste is astringent and slightly sweet. The plant is seedless and hardy, growing in a variety of climates and soils. Khat can be grown in droughts where other crops have failed and also at high altitudes. Khat is harvested throughout the year. Planting is staggered to obtain a continuous supply (Luqman \& Danowski, 1976). Khat is mainly grown in Ethiopia, Kenya, Yemen, Somalia, Sudan, South Africa and Madagascar. It has also been found in Afghanistan and Turkestan. Previously, khat leaves were available only near to where they were grown. Recently, improved roads and air transport have allowed a much wider distribution. Khat is harvested in the early hours of the morning and sold in markets in late morning. It is presented as a bundle of twigs, stems and leaves, wrapped in banana leaves to preserve freshness (Fig. 1).

\section{History of consumption and 'medical' use}

Ethiopia is thought to be the country of origin of khat use. The chewing of khat leaves probably pre-dates the use of coffee. The earliest written record of the medical use of khat appears to be in the New Testament. Khat has been used to treat various ailments, including relieving the symptoms of depression. Some believe it to be a dietary requirement.

\section{Legal aspects of use}

In Kenya, Yemen, Uganda, Ethiopia and Madagascar prohibition has resulted in increased illegal importation. When prohibition was replaced in Somalia by import duty, khat chewing became a very common habit within a few years. In Saudi Arabia khat cultivation and consumption are forbidden and the ban is strictly enforced. However, today, khat circulates freely in all of the above countries. In some countries, khat chewing is allowed, in others it is officially banned but there is no law enforcement (Elmi, 1983).

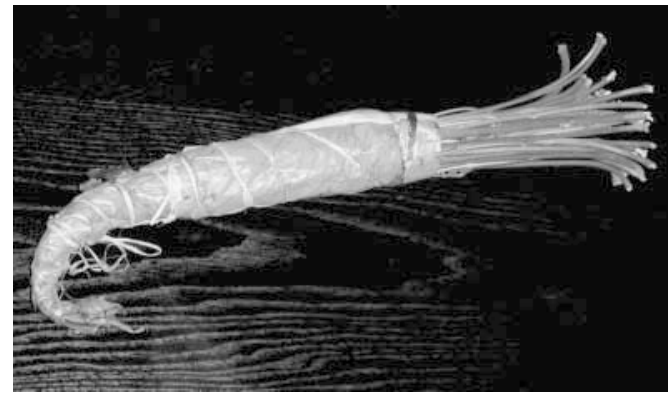

Fig. 1 Bundle of khat. The usual length of a bundle is $30-40 \mathrm{~cm}$.

Glenice Cox is a specialist registrar on the Oxford Higher Psychiatric Training Scheme, and she has worked with Dr Rampes in Southall. Hagen Rampes is a general adult psychiatrist with the West London Mental Health NHS Trust (John Conolly Wing, Southall, Middlesex UB1 3EU, UK. Tel.: 0208354 8014; fax: 0208354 8887; e-mail: Hagen.Rampes@wlmhst.nhs.uk), where he is responsible for the catchment area of Southall. He is also an honorary clinical senior lecturer at Imperial College of Science, Technology and Medicine, London. 


\section{Obtaining khat in Western countries}

In the UK, khat trade, possession and use are not illegal. Although cathinone and cathine, the major active constituents, are scheduled as class C drugs, khat itself is not a prohibited substance. An offence is committed only if cathinone or cathine are isolated from the plant. About 7 tonnes of khat pass through Heathrow airport each week, and smaller amounts are imported through other airports. Immigrants have spread the use of khat to the UK, Europe and USA. Heathrow airport serves as a hub for the reexport of khat to other European countries (Goudie, 1987).

\section{Ingestion of khat}

The vast majority of those ingesting khat do so by chewing. Only a small number ingest it by making a drink from dried leaves, or, even more rarely, by smoking dried leaves. The chewer fills his or her mouth with leaves and stalks, and then chews slowly and intermittently to release the active components in the juice, which is then swallowed with saliva. The plant material is chewed into a ball, which is kept for a while in the cheek, causing a characteristic bulge (Nencini et al, 1986).

\section{Behaviours associated with the ritual of khat chewing}

Khat chewing usually takes place in groups in a social setting. Only a minority frequently chew alone. A session may last for several hours. During this time chewers drink copious amounts of non-alcoholic fluids such as cola, tea and cold water. In a khat chewing session, initially there is an atmosphere of cheerfulness, optimism and a general sense of well-being. After about 2 hours, tension, emotional instability and irritability begin to appear, later leading to feelings of low mood and sluggishness. Chewers tend to leave the session feeling depleted.

\section{Reasons for chewing khat}

Chewing khat is both a social and a culture-based activity. It is said to enhance social interaction, playing a role in ceremonies such as weddings. In Yemen, Muslims are the most avid chewers. Some believe that chewing facilitates contact with Allah when praying. However, many Christians and Yemenite Jews in Israel also chew khat. Khat is a stimulant and it is used to improve performance, stay alert and to increase work capacity (Kalix, 1984). Workers on night shifts use it to stay awake and postpone fatigue. Students have chewed khat in an attempt to improve mental performance before exams. Yemeni khat chewers believe that khat is beneficial for minor ailments such as headaches, colds, body pains, fevers, arthritis and also depression (Kennedy et al, 1983).

\section{Epidemiology of khat use}

In khat-producing African countries Elmi (1983) studied khat chewers in the two main cities in Somalia: Mogadishu and Hargeisa. The results showed that traders and businessmen carried out business transactions during khat parties, whereas for the unemployed it was a way of overcoming feelings of frustration and boredom. In Somalia, Alem et al (1999) found that more men habitually chewed than women: $75 \%$ of men chewed khat regularly compared with only $7-10 \%$ of women. Kennedy et al's (1983) Yemen studies had similar findings. Overall, it seems that khat is less appealing to women, although in Somalia chewing has recently become more popular among middle-class and educated women.

\section{Use by immigrants in the UK and other Western countries}

In the UK, the chewing of khat is largely confined to ethnic communities accustomed to its use, such as the Somali community (Gough \& Cookson, 1984). Wherever Somalis reside, khat is available. Griffiths (1998) carried out a survey of 207 Somalis living in London: $78 \%$ of men and $76 \%$ of women had used khat and $6 \%$ were chewing on a daily basis; the average frequency of use was 3 days per week. Of those surveyed, $76 \%$ were using more khat in London than they had in Somalia; $20 \%$ had started chewing khat since coming to London. Participants felt that community use was greater in the UK than in Somalia. The explanation most commonly given was that, because of high unemployment, more free time was available for chewing. There was also a desire to maintain cultural identity by chewing khat.

\section{Pharmacology of khat}

\section{Active constituents}

Khat contains more than 40 alkaloids, glycosides, tannins, amino acids, vitamins and minerals (Halbach, 1972). Most of the effect of chewing khat is thought to come from two phenylalkylamines cathinone and cathine - which are structurally related to amphetamine (Nencini et al, 1984). The 


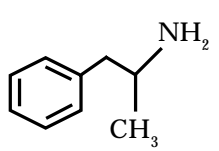

Amphetamine

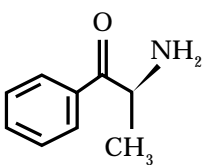

Cathinone
Fig. 2 Chemical structures of amphetamine and cathinone.

presence of amphetamine and caffeine in khat has been excluded. A number of other constituents, including cathidine, eduline and ephedrine, have been identified, but it is unlikely that any of these, except tannin, play a role in khat's effects (Giannini et al, 1986). The structure of cathinone and its relationship to amphetamine are illustrated in Fig. 2.

Cathinone has been termed a 'natural amphetamine'. It produces sympathomimetic and central nervous system stimulation analogous to the effects of amphetamine, hence its similar clinical effects. The difference in effect is due to slight pharmacodynamic variations between the stimulating substances, to other plant constituents (mainly tannins), and to differences in dosage and the mode of consumption.

\section{Actions of cathinone and cathine}

Cathinone is also named (-)-alpha-aminopropiophenone. It is considered to be the most active ingredient of khat. It has been isolated and synthesised and its effects have been shown to be similar to amphetamine, but with a lower potency. Cathinone is estimated to be 7-10 times more potent than cathine. It is difficult to synthesise, therefore it is unsuitable for marketing as a pure substance for drug misuse (Nencini et al, 1989).

Cathine is also named (+)-norpseudoephedrine and phenylpropanolamine. It had previously been isolated from the plant ephedra, which has effects similar to those of khat. Cathine has a milder psychostimulant action than cathinone and the effects last for only a short time, so the user must chew leaves almost continuously. It plays only a minor role in the action of khat, but it is cathine that is responsible for the unwanted systemic effects. Normally, fresh leaves contain a higher proportion of the desirable cathinone. Where the content of cathine is relatively higher, the cathine causes more unwanted systemic effects. On drying, cathinone breaks down into cathine. Therefore khat chewers prefer fresh leaves that contain a higher proportion of cathinone to cathine, so that they obtain a better stimulation with fewer systemic adverse effects.

\section{Modes of action}

The constituents of khat have been shown to exert their effects on two main neurochemical pathways: dopamine and noradrenalin. It has also been postulated that, like amphetamine, cathinone releases serotonin in the central nervous system. Both cathinone and amphetamine induce release of dopamine from central nervous system dopamine terminals and thus increase the activity of the dopaminergic pathways (Kalix \& Braenden, 1985). Cathinone has a releasing effect on noradrenalin storage sites, which supports the conclusion that cathinone facilitates noradrenalin transmission. Drake (1988) also proposed that cathinone and cathine cause inhibition of noradrenalin uptake.

\section{Pharmacokinetics}

The euphoric effect appears shortly after the chewing begins, suggesting absorption from the oral mucosa. The effect of cathinone is maximum after 15-30 minutes. Metabolism of cathinone is rapid, occurring mainly during first passage through the liver. Only a small fraction (about 2\%) appears unchanged in the urine. Most cathinone is metabolised to norephedrine and is excreted in this form. The rate of inactivation is about the same as the rate of absorption, which limits the cathinone blood levels attainable by chewing.

Cathine has a slower onset of action, with a serum half-life in humans of about 3 hours. It is excreted unchanged in the urine within about 24 hours. When taking khat, large amounts of non-alcoholic drinks are consumed. There is pharmacological synergism with drinks containing methylxanthines (e.g. tea and cola), which therefore enhances the effects of khat.

\section{Addiction, tolerance and withdrawal}

Cathinone is the dependence-producing constituent of khat leaves. It is a reinforcer and maintains very high rates of responding in animal experiments (Kalix \& Khan, 1984). Debate exists as to whether khat, like amphetamines, can actually cause dependence. Some authors describe a psychological dependence rather than a physical one (Halbach, 1972). Tolerance to khat practically does not occur; if it does, the doses are increased only very slowly. This may be due to the intrinsic properties of khat or to the physical limits on the amount that can be consumed (Kalix, 1988).

There are conflicting opinions regarding the existence of a withdrawal syndrome. Physical 
withdrawal symptoms are documented, including lassitude, anergia, nightmares and slight trembling, which appear several days after ceasing to chew. Depressive disorder, sedation and hypotension are sometimes seen after withdrawal of khat. In one study only $0.6 \%$ of khat chewers continued to use in order to prevent withdrawal symptoms (Alem et al, 1999).

\section{Psychological sequelae of chewing khat}

Chewers report their subjective experiences of khat use in a positive way when consuming small amounts. They describe a feeling of well-being, a sense of euphoria, excitement, increased energy levels, increased alertness, increased ability to concentrate, improvement in self-esteem and an increase in libido. Also experienced are an enhanced imaginative ability and capacity to associate ideas, an improvement in the ability to communicate and a subjective improvement in work performance. After chewing ceases, unpleasant after-effects tend to dominate the experience: insomnia, numbness, lack of concentration and low mood. Some chewers also experience unpleasant effects during the chewing process, describing anxiety, tension, restlessness and hypnagogic hallucinations.

Objectively, chewers can be seen to show a range of experiences, from minor reactions to the development of a psychotic illness. Minor reactions include over-talkativeness, overactivity, insomnia, anxiety, irritability, agitation and aggression.

Broadly, the main psychiatric manifestations linked to the use of khat are a short-lived schizophreniform psychotic illness, mania (Yousef et al, 1995) and, more rarely, depression (Pantelis et al, 1989). On occasions these presentations are associated with episodes of self-harm or harm to others. Owing to the mode of consumption, the dose of khat tends to be self-limiting, unlike amphetamines, which are available in a pure form for oral or parenteral administration. Therefore toxic psychosis as a result of excessive use is much less frequent with khat than with amphetamines.

\section{Epidemiology and reporting of psychiatric complications}

Most reports are of cases of psychosis and suggest a low incidence. The impression of low incidence may reflect the fact that in countries where it is most used, health facilities are lacking and people are managed at home by their family.

Dhadphale \& Omolo (1988) studied psychiatric morbidity among khat users. They found that when khat was chewed in moderate quantities there was no excess morbidity, but when the amount chewed per day was greater than two bundles, morbidity was significantly increased. Other research (Critchlow \& Seifert, 1987; Alem \& Shibre, 1997) confirms our clinical experience that adverse effects are dose-related. However, many researchers consider that khat precipitates a psychotic illness in those who are already predisposed.

Psychiatric care of these patients can be difficult, leading to less-than-optimal care. This is because patients with the 'dual diagnosis' of khat misuse and a psychotic illness are often not recognised by substance misuse services. Furthermore, these services have had little experience with khat misuse in the UK. Khat users with psychosis therefore frequently present to general adult psychiatry services.

\section{Psychoses}

The literature outlining the characteristics of psychoses following the use of khat describes two main types: a paranoid or schizophreniform psychosis (similar to an amphetamine-like psychosis) and a manic psychosis.

\section{Schizophreniform psychosis}

Case histories typically describe a recent increase in khat use or heavy consumption. The patients typically present with paranoid delusions, fear, a hostile perception of the environment, auditory hallucinations (frequently of a persecutory or threatening type), ideas of reference, thought alienation and a tendency to isolate themselves, or alternatively displaying aggressive behaviour towards others. If khat consumption is ceased at this time, resolution of symptoms usually occurs within a short period (3-11 days), but there is a tendency for the psychosis to recur if khat chewing is restarted.

\section{Manic psychosis}

Several authors have described a manic-type psychosis. Giannini \& Castellani (1982) reported the first case in the USA. The patient presented with hyperactivity, shouting, pressure of speech, grandiose delusions with flight of ideas and tangential thought processes, and a labile mood varying from euphoria to anger. The patient had used khat for the first time, chewing about 24 leaves (this is equivalent to a single dose of khat). Symptoms subsided spontaneously within about 8 hours of chewing. Drake (1988) also described a case of mania following prolonged chewing, with the patient 'running amok'. 
Our own experience is of working in an adult mental health unit in Southall, west London. This area of London has a high number of Somali immigrants and refugees, a large proportion of whom are unemployed. Khat chewing in Somali cafés is a common pastime. Admissions to hospital due to khat-induced psychosis are not infrequent, usually associated with a recent increase in the amount consumed. Presentations are frequently similar to an amphetamine-like psychosis, with disturbed and violent behaviour. On occasions this requires compulsory admission to hospital under the Mental Health Act 1983, often involving the use of Section 136 by the police.

Confusional states are rare; usually the paranoid reactions occur in clear consciousness. Kennedy et al (1983) stated that confusion and disorientation may occur as a transient phenomenon in the khat user, even without psychosis. Dhadphale \& Omolo (1988) suggested that the people Kennedy studied were in fact exhibiting acute drug intoxication and were in a state of delirium. The level of sympathetic arousal is higher in acute khat intoxication than in heavy prolonged use, where some sympathetic tolerance occurs; this might be helpful in distinguishing between these situations (McLaren, 1987).

\section{Depression}

Several authors describe depression associated with chewing khat, but nearly all of these reports document that the depression arises on cessation of use. This has, on occasions, been associated with self-harm and suicide. Such behaviour has also been reported following amphetamine use and cessation (Pantelis et al, 1989).

\section{Self-harm, suicide and violence}

Self-harm and suicide have been reported in the literature, although these are rare. Each has been documented during both chewing and the subsequent intoxication phase. One patient bit himself and repeatedly banged his head against the wall. Another patient took an overdose because of the distress caused by his paranoid symptoms. Suicide has been described by several authors in the context of a 'withdrawal state'.

Violent acts, including homicide, are also documented, usually in the context of paranoid or persecutory delusions. Alem \& Shibre (1997) described a case where a patient murdered one of his wives and his daughter. He was acquitted of murder by the court, as he was deemed not responsible for his actions. Alem et al (1999) also reported a case of combined homicide and suicide after chewing increased amounts of khat.

\section{Effects of long-term khat use}

Intoxication with khat is self-limiting, but chronic consumption can lead to impairment of mental health, possibly contributing to personality disorders and 'mental deterioration' (Kalix \& Braenden, 1985). Conversely, Dhadphale \& Omolo (1988) reported no increased long-term psychiatric morbidity among khat chewers.

\section{Physical sequelae}

The physical effects of khat are well documented and can be described according to the physiological systems affected (Table 1$)$.

\section{Table 1 The physical adverse effects of khat}

Cardiovascular system

Respiratory system

Gastrointestinal system

Hepatobiliary system

Genitourinary system

Obstetric effects

Metabolic and endocrine effects

Central nervous system
Tachycardia, arrhythmias, palpitations, hypertension, vasoconstriction, ischaemia, infarction, pulmonary oedema, cerebral haemorrhage (Gianni et al, 1986)

Exacerbation of pre-existing cardiac conditions

Bronchitis, tachypnoea, dyspnoea, tuberculosis

Dry mouth, polydipsia, dental caries, periodontal disease, chronic gastritis, gastric ulcer, constipation (54\% in one study Elmi, 1983), paralytic ileus, anorexia, weight loss, increased risk of upper gastrointestinal malignancy

Cirrhosis

Spermatorrhoea, impotence, libido change, urinary retention (complicated by diuresis from increased fluid intake)

Low birth weight, stillbirths, impaired lactation

Hyperthermia, perspiration, hyperglycaemia

Dizziness, impaired concentration, insomnia, headaches, migraine, midriasis, conjunctival congestion, impaired motor coordination, fine tremor, stereotypical behaviour (Kalix, 1984) 


\section{Socio-economic effects}

In communities where khat is used regularly it has negative impacts on health and socio-economic conditions.

\section{Decreased productivity}

Khat chewing leads to loss of work hours, decreased economic production, malnutrition and diversion of money in order to buy further khat. This is indirectly linked to absenteeism and unemployment, which may in turn result in a fall in overall national economic productivity. It is reported that habitual khat chewing has led to decreased productivity in Ethiopia, Somalia, Uganda and Kenya (Giannini et $a l, 1986)$. Others argue that moderate use improves performance and increases work output, owing to the stimulant and fatigue-postponing effects. Consequently, working hours and possibly productivity can decrease when khat is not used, because of anergia and reduced motivation.

\section{Family and marital problems}

Kalix \& Khan (1984) estimated that about one-third of all wages were spent on khat in Djibouti. Many men secure their daily portion of khat at the expense of vital needs, indicating dependence. Family life is harmed because of neglect, dissipation of family income and inappropriate behaviour. Khat is quoted as a factor in one in two divorces in Djibouti. Acquisition of funds to pay for khat may lead to criminal behaviour and even prostitution (Elmi, 1983).

\section{Economic perspectives of growing khat}

The urban poor are the most negatively affected, but in rural areas scarce arable land and irrigation water are used for khat instead of for nutrient plants and the export crop, coffee. However, the economic benefit from selling and exporting khat is said to be high.

\section{Khat and cigarettes, alcohol and illicit drugs}

A Home Office survey (Griffiths, 1998) noted that $60 \%$ of Somali khat chewers in London also smoked cigarettes; $75 \%$ of these were men, smoking 5-45 cigarettes per day. Only a minority used any other drugs and the most common was cannabis, used by $6 \%$ of the sample.

Heavy chewers use khat to stay awake, increase productivity or feel 'high'. They then need alcohol to rest, calm their nerves or sleep: alcohol is used to counteract the stimulating effect and sleeplessness caused by the khat. Omolo \& Dhadphale (1987) investigated the use of alcohol with khat, and surveyed 100 general hospital out-patients in Kenya: 29 chewed khat, and of these, 20 also drank alcohol, 12 of them heavily. Khat has been linked to the misuse of other drugs. In Somalia, high rates of concomitant heroin and cocaine use were found, but this was thought to be associated with the traditional availability of these drugs in that country.

\section{Interactions between khat and prescribed medication}

Khat can interact with therapeutic drugs. Phenylpropanolamine, which can display synergism with khat, is widely available in over-the-counter cold and appetite-suppressant preparations and in prescription drugs. The use of monoamine oxidase inhibitors is to be avoided in khat users, as this is likely to precipitate a dangerous level of sympathetic stimulation, possibly leading to a hypertensive crisis. Reactions to surgical anaesthetics may be bizarre in the chronic khat user and during the postoperative period the patient may be agitated and overaroused.

\section{Detection of khat}

\section{Urinalysis}

In the UK, a commercially available biochemical test to detect khat constituents in the urine can now be used for confirmation of a suspected khat-induced state. Initially, a rapid screen by immunoassay detects amphetamine-related compounds. Then gas chromatography mass spectrometry is performed. This cannot detect cathinone directly, but a positive result indicates the presence of norephedrine, a cathinone metabolite. The test will give a positive result for up to about 48 hours after consumption of khat, although this is dependent on many factors, for example chronic consumption as opposed to a single episode of use, the quantity taken, the user's metabolism, and dilution of urine following consumption of fluids. The test is highly sensitive, but not highly specific, and there are some crossreactions with other metabolites (Lehmann et al, 1990). However, in the context of the clinical presentation together with the history of khat consumption, the urinalysis is a useful additional test. In many areas urine testing is not available, and an accurate history of (increased) khat consumption prior to the onset of clinical symptoms is equally important, if not more so. 


\section{Management of psychiatric problems related to khat use}

There is a paucity of information in the literature regarding treatment of khat-induced psychiatric illnesses. Before the advent of antipsychotic drugs, and possibly currently in areas where access to modern health care is poor or not culturally acceptable, relatives and friends of patients manage the situation by locking them in their homes until the condition subsides, which may take several days. They sometimes have to use physical restraint for the patient's and others' safety.

\section{Reports of pharmacological management}

Many episodes of khat-induced psychosis resolve spontaneously within 1-2 days of cessation of use; sometimes symptoms subside within less than 24 hours. Most clinicians agree that, even when antipsychotics are given, the improvement is attributed to stopping the khat rather than taking antipsychotics. Occasionally, a psychotic episode may require longer periods of treatment (i.e. several weeks) with antipsychotics for full resolution.

Case reports of effective resolution of symptoms describe treatment with thioridazine at doses of 300-600 mg per day for 1 week, haloperidol (doses not specified) and, in one case, electroconvulsive therapy (Alem \& Shibre, 1997). For several cases the duration of treatment with antipsychotics was not specified; however, reports of resolution of symptoms (dependent on cessation of khat use) were given as 'within 1 week'. Treatment with new or atypical antipsychotics has not yet been reported. Box 1 lists practice points for clinicians managing patients who misuse khat. The following fictional case report describes a common situation.

\section{Fictional case report}

A 22-year-old Somali male was admitted via the accident and emergency department. He had poor appetite, insomnia and grandiose delusions. He had been talking and laughing to himself, and admitted to experiencing visual hallucinations in the form of scenes of people being tortured.

He admitted that he had chewed khat intermittently for about 6 years. His use of khat had increased for several weeks prior to admission.

On the ward he was verbally and physically aggressive. He was prescribed zuclopenthixol acetate. Oral regular antipsychotic medication was started with haloperidol and subsequently depot zuclopenthixol dihydrochloride $200 \mathrm{mg}$ intramuscularly weekly. After initially responding with a decrease in his psychotic symptoms, he absconded from the

\section{Box 1 Practice points}

- Enquire about use of khat in Somali or any other East African patients

- Khat use can be tested by urine sample on admission

- Use of benzodiazepine and antipsychotic medication is often necessary

- Pure khat-induced psychosis resolves rapidly

- Mental and behavioural disorders due to the use of stimulants (khat) is often a comorbid diagnosis in such patients

ward. He returned later exhibiting bizarre behaviour and worsening of his mental state. His khat bundles were confiscated and disposed of. He admitted to chewing khat during the period of absconsion.

Continued regular depot medication led to a gradual decrease and disappearance of his psychotic symptoms over the next 4 weeks. He abstained from further use of khat (confirmed by negative urinalysis) and was discharged 8 weeks after admission.

\section{References}

Alem, A. \& Shibre, T. (1997) Khat induced psychosis and its medico-legal implication: a case report. Ethiopian Medical Journal, 35, 137-141.

—, Kebede, D. \& Kullgren, G. (1999) The prevalence and socio-demographic correlates of khat chewing in Butajira, Ethiopia. Acta Psychiatrica Scandinavica Supplementum, 100, 84-91.

Critchlow, S. \& Seifert, R. (1987) Khat-induced paranoid psychosis. British Journal of Psychiatry, 150, 247-249.

Dhadphale, M. \& Omolo, O. E. (1988) Psychiatric morbidity among khat chewers. East African Medical Journal, 65, 355359.

Drake, P. H. (1988) Khat-chewing in the Near East (letter). Lancet, $i, 532-533$.

Elmi, A. S. (1983) The chewing of khat in Somalia. Journal of Ethnopharmacology, 8, 163-176.

Giannini, A. J. \& Castellani, S. (1982) A manic-like psychosis due to khat (Catha edulis Forsk). Journal of Clinical Toxicology, 19, 455-459.

-, Burge, H., Shaheen, J. M., et al (1986) Khat: another drug of abuse? Journal of Psychoactive Drugs, 18, 155-158.

Goudie, A. J. (1987) Importing khat, legal but dangerous (letter). Lancet, ii, 1340-1341.

Gough, S. P. \& Cookson, I. B. (1984) Khat induced schizophreniform psychosis in UK (letter). Lancet, $i, 455$.

Griffiths, P. (1998) Oat use in London: a study of khat use among a sample of Somalis living in London (Home Office Paper 26). London: Stationery Office.

Halbach, H. (1972) Medical aspects of the chewing of khat leaves. Bulletin of the World Health Organization, 47, 2129.

Kalix, P. (1984) The pharmacology of khat. General Pharmacology, 15, 179-187.

- (1988) Khat: a plant with amphetamine effects. Journal of Substance Abuse and Treatment, 5, 163-169.

— \& Braenden, O. (1985) Pharmacological aspects of the chewing of khat leaves. Pharmacological Reviews, 37:2, 149164.

— \& Khan, I. (1984) Khat: an amphetamine-like plant material. Bulletin of the World Health Organization, 62, 681686. 
Kennedy, J. G., Teague, J., Rokaw, W., et al (1983) A medical evaluation of the use of qat in North Yemen. Social Science and Medicine, 17, 783-793.

Lehmann, T., Geisshüsler, S. \& Brenneisen, R. (1990) Rapid TLC identification test for khat (Catha edulis). Forensic Science International, 45, 47-51.

Luqman, W. \& Danowski, T. S. (1976) The use of khat (Catha edulis) in Yemen: social and medical observations. Annals of Internal Medicine, 85, 246-249.

McLaren, P. (1987) Khat psychosis (letter). British Journal of Psychiatry, 150, 712-713.

Nencini, P., Ahmed, A. M., Aminconi, G., et al (1984) Tolerance develops to sympathetic effects of khat in humans. Pharmacology, 28, 150-154.

— - \& Elmi, A. S. (1986) Subjective effects of khat chewing in humans. Drug and Alcohol Dependence, 18, 97-105.

-, Grassi, M. C., Botan, A. A., et al (1989) Khat chewing spread to the Somali community in Rome. Drug and Alcohol Dependence, 23, 255-258.

Omolo, O. E. \& Dhadphale, M. (1987) Alcohol use among khat (Catha) chewers in Kenya. British Journal of Addiction, 82, 97-99.

Pantelis, C., Hindler, C. G. \& Taylor, J. C. (1989) Use and abuse of khat (Catha edulis): a review of the distribution, pharmacology, side effects and a description of psychosis attributed to khat chewing. Pharmacological Medicine, 19, 657-668.

Yousef, G., Huq, Z. \& Lambert, T. (1995) Khat chewing as a cause of psychosis. British Journal of Hospital Medicine, 54, $322-326$

\section{Multiple choice questions}

1 The main active constituents of khat include:

a cathine

b amphetamine

c tannins

d cathinone

e miraa.

2 Khat has actions similar to those of:

a ephedrine

b caffeine

c pseudoephedrine

d amphetamine

e noradrenalin.
3 Physical complications of khat include:

a diarrhoea

b tachycardia

c tremor

d drowsiness

e insomnia.

4 Reasons for chewing khat given by users include:

a to enhance social interaction

b to improve sexual performance

c to facilitate religious prayer

d to increase mental performance

e to treat low mood.

5 Khat psychosis:

a might not need drug treatment

b might be of a manic type

c might require admission to hospital

d might be considered similar to amphetamine psychosis

e might result in harm to self or others. 